\title{
Separation of Powers and Political Budget Cycles*
}

\author{
Alejandro Saporiti ${ }^{\dagger} \quad$ Jorge M. Streb ${ }^{\ddagger}$
}

November 2003

\begin{abstract}
From a theoretical viewpoint, political budget cycles (PBC) arise in equilibrium when rational voters are imperfectly informed about the incumbent's competency and the incumbent enjoys discretionary power over the budget. This paper focuses on the second condition, examining how executive discretion is affected by the budgetary process under separation of powers. We specifically model PBC in the composition of government spending. The main result is that effective checks and balances in the budgetary process curb PBC. The institutional features of the executive-legislature bargaining game, namely, the actual agenda-setting authority, the status quo location and the degree of legislative oversight and control of the implementation of the budgetary law, play critical roles for the existence and the size of PBC. These results are consistent with recent empirical findings, which show that $\mathrm{PBC}$ are more pronounced in developing countries, where there are also less effective checks and balances.
\end{abstract}

JEL Classification: D72, D78.

Keywords: Rational political budget cycles; budget composition; separation of powers; checks and balances; budgetary process.

*We warmly thank Walter Cont for his very helpful and insightful comments. We also appreciate the remarks made by Martín Besfamille, Pablo Sanguinetti, and participants at the AAEP meeting in Mendoza, the Economic Conference of the Banco Central del Uruguay, and seminars at UdeSa and UTDT.

${ }^{\dagger}$ Department of Economics, Queen Mary, University of London, Mile End Road, London E1 4NS, UK. E-mail: a.d.saporiti@qmul.ac.uk.

${ }^{\ddagger}$ Universidad del CEMA, Av. Córdoba 374, C1054AAP Buenos Aires, Argentina. E-mail: jms@ucema.edu.ar. 


\section{Introduction}

The literature on political budget cycles (PBC) studies cycles in fiscal policies generated by the electoral process. These cycles may be in the composition of public spending, in the size of the total budget, and in the choice of taxes or debt to finance the budget.

At a theoretical level, the literature on rational $\mathrm{PBC}$ has made significant progress analyzing informational issues. ${ }^{1}$ However, a formal analysis of PBC under separation of powers is still lacking. In effect, in this literature it is implicitly assumed that fiscal decisions are taken unilaterally by the executive, without any kind of institutional constraints. None of the existing models of rational PBC has incorporated the legislature as a second player in the policy-making process followed to set fiscal policy.

The assumption of concentration of powers in the hands of the executive is not innocuous. The credibility problem this produces is at the heart of electoral cycles in fiscal policy. Under separation of powers, the design of appropriate checks and balances may provide the kind of commitment device that allows the executive to credibly compromise to optimal policies, by requiring joint agreement in the policy-making process.

This paper formally tackles the impact of separation of powers on PBC in the composition of government spending, though the model can also be applied to other aspects of fiscal policy. To the best of our knowledge of the field, this is the first time such goal is carried out. ${ }^{2}$

As in Rogoff and Sibert (1988), Rogoff (1990) and others, under asymmetric information the political incumbent faces, before elections, an incentive to boost the supply of more visible (consumption) public goods, in the hope that voters will attribute the boost to its competence and will reelect it for another term. However, instead of assuming an all-powerful executive, our model introduces a legislature into the policy-making process, reflecting the existence of separation of powers.

Separation of powers brings into play a system of checks and balances. In this regard, in all constitutional democracies a relatively fixed and well-known procedure is followed every year to draft, approve and implement the annual budget of expenditures and the public resources to finance it. ${ }^{3}$ In this paper this procedure is

\footnotetext{
${ }^{1}$ See Shi and Svensson (2003) for a recent review.

${ }^{2}$ The interplay of various policy-makers has been considered in the analysis of the electoral cycle in monetary policy. In Lohmann (1998a), several regional central bankers interact, while in Drazen (2001) there is both a fiscal authority and a monetary authority.

${ }^{3}$ Alesina and Perotti (1995) review the literature on budget processes and institutions. Empirically, Alesina et al. (1999) point out that budget institutions have a significant role for explaining the cross-country variance of fiscal experiences in Latin America. However, this literature does not relate budget institutions to rational PBC.
} 
depicted through a simple bargaining game between the executive and the legislature, which relies ultimately on the agenda-setter model of Romer and Rosenthal (1978, 1979). ${ }^{4}$ Persson, Roland and Tabellini (1997) use a similar framework to analyze separation of powers, but as a mechanism to control the rents politicians appropriate from being in office.

Our main result is that effective checks and balances in the budgetary process curb PBC. Institutional features of the executive-legislature bargaining game, namely, the actual agenda-setting authority, the status quo location and the degree of the legislative oversight and control of the implementation of the budgetary law, play critical roles for the existence and magnitude of electoral cycles in fiscal policy.

From an empirical viewpoint, the analysis carried out in this paper may be useful to understand why political fiscal cycles tend to be more pronounced in developing countries and, particularly, in new democracies. ${ }^{5}$ While not focusing on separation of powers and budget institutions, recent empirical evidence has shown that many aspects of the political system (namely, electoral rules, forms of government, level of democracy, degree of electoral competitiveness, information and transparency, and voters' previous experience with electoral politics) have a significant impact over fiscal cycles. Furthermore, Schuknecht (1996) also suggests that there should be more room for fiscal manipulation in developing countries because checks and balances are usually weaker in those countries. This last connection between the political process and PBC is precisely the one that we formally explore in this work.

The paper is organized as follows. Section 2 presents the model. The equilibrium analysis is carried out in Section 3. Finally, Section 4 briefly summarizes the main results and outlines directions for future research.

\section{The model}

Consider an infinite-horizon society composed by a large but finite number of identical individuals, labeled $i=1,2, \ldots, n$. Let $t$ denote time, $t \in T \equiv T_{1} \cup T_{2}$, where $T_{1}$ is the set of all odd positive integers (electoral periods) and $T_{2}$ is the set of all even positive integers (post-electoral periods).

In every period $t \in T$, individual $i$ plays roles both as a consumer and as a citizen. The representative consumer derives utility from two types of public goods, which differ in the timing of their production: a visible (consumption) good $g_{t} \in \Re_{+}$, instantaneously supplied, and a less visible (capital) good $k_{t+1} \in \Re_{+}$,

\footnotetext{
${ }^{4}$ See Rosenthal (1990) for a survey on this literature.

${ }^{5}$ See, for example, Shi and Svensson (2002a, 2002b), Persson and Tabellini $(2002,2003)$ and Brender and Drazen (2003).
} 
provided at the end of period $t$. The capital good cannot be observed until it is in place.

To simplify the equilibrium characterization, it is assumed that the representative consumer's per-period payoff is given by a Cobb-Douglas utility function $u: \Re_{+} \times \Re_{+} \rightarrow \Re$,

$$
u\left(g_{t}, k_{t+1}\right)=\left(g_{t}\right)^{\alpha}\left(k_{t+1}\right)^{1-\alpha},
$$

where $0<\alpha<1$.

In each period $t \in T$, the economy is subject to the budget constraint

$$
\gamma_{t}+\kappa_{t}=\tau
$$

where $\gamma_{t}, \kappa_{t} \in \Re_{+}$denote actual budget expenditures on consumption and capital goods, respectively, and $\tau \in \Re_{++}$is a fixed sum of tax revenues (the size of the public sector).

The production of public goods is such that the same amount of per-period public resources can be transformed into either one unit of $g_{t}$ or one unit of $k_{t+1}$. Their effective provision is affected by a random variable $\theta_{t}$ that represents the competence of the executive, the agent in charge of this task. Public goods are thus given by

$$
\begin{gathered}
g_{t}=\theta_{t} \gamma_{t}, \\
k_{t+1}=\theta_{t} \kappa_{t} .
\end{gathered}
$$

As in Rogoff and Sibert (1988), Rogoff (1990) and others, actual competence is assumed to be partially lasting, following a first-order moving average process $(\mathrm{MA}(1))$,

$$
\theta_{t}=\bar{\theta}+\varepsilon_{t}+\varepsilon_{t-1}
$$

where $\varepsilon$ is a random iid variable and $\varepsilon_{t}$ denotes the period $t$ realization of $\varepsilon$. The interpretation of these competence shocks is that, although competence is in principle persistent, it comprises multiple dimensions that are not necessarily correlated. The specific challenges a government faces change exogenously over time, making actual competence contingent to these changes.

The variable $\varepsilon$ is uniformly distributed over the interval $\left[-\frac{1}{2 \xi}, \frac{1}{2 \xi}\right]$, with expected value $E(\varepsilon)=0$ and density function $\xi>0$. A higher value of $\varepsilon$ corresponds to a more competent politician, since the same per-period tax revenues can be used to provide more of both public goods. The marginal (conditional on $\left.\varepsilon_{t-1}\right)$ probability distribution of $\theta_{t}, \tilde{F}\left(\theta_{t}\right)=F\left(\theta_{t} \mid \varepsilon_{t-1}\right)$, is also uniform, with support $\Theta_{t}=\left[\bar{\theta}+\varepsilon_{t-1}-\frac{1}{2 \xi}, \bar{\theta}+\varepsilon_{t-1}+\frac{1}{2 \xi}\right], \tilde{F}^{\prime}>0$ for all $\theta_{t} \in \Theta_{t}, \tilde{F}^{\prime \prime}=0$, and $E_{t-1}\left(\theta_{t}\right)=\bar{\theta}+\varepsilon_{t-1}$. Henceforth, it is assumed that $\bar{\theta}>1 / \xi$, so $\theta_{t}>0$ and (3) and (4) are well-defined. 


\subsection{Separation of powers}

In contrast to much of the theoretical literature on $\mathrm{PBC}$, in this paper the policymaking process carried out to set the mix of public expenditures involves the interaction of two political agents, labeled $E$ and $L$. These agents are the current leaders, or incumbents, of the two branches of government, the executive and the legislature.

In each branch, a leader's term lasts two periods. Every other period, a random iid recognition rule $\hat{L}: T_{1} \rightarrow\{1,2 \ldots, n\}$ selects a new leader for the legislature from the set of all possible political candidates, which coincides here with the set of citizens. ${ }^{6}$ On the other hand, the electorate removes or confirms the executive leader in an explicit electoral contest. If the executive incumbent is confirmed, it controls this branch for another term. Otherwise, a new policy-maker is randomly recognized according to the rule $\hat{E}: T_{1} \rightarrow\{1,2, \ldots, n\}$. No limit is set on the number of times incumbents can run for reelection.

Incumbents' payoffs are as follows. They receive, like other citizens, utility from the consumption of public goods. They also receive an exogenous rent $\chi>0$ at the beginning of each term in office (i.e., in post-electoral periods), reflecting the satisfaction from being in power. These rents will be the source of conflict between the incumbents and the electorate. In Lohmann's (1998b) words, this variable reflects the strength of the electoral goal.

\subsection{Checks and balances}

The process for setting the budgetary mix under separation of powers involves a specific system of checks and balances. At the stage of budget formulation and approval, the institutional arrangement gives $E$ the right to make a budget allocation proposal, but it requires the motion to be accepted by $L$. If no amendment rights exist, $L$ faces a take-it-or-leave-it proposal, where the reversion outcome $\bar{\gamma}$ (the status quo) in case of rejection is exogenously specified. The legislature might be allowed to amend the executive's proposal, but then the amended proposal can be vetoed by $E .^{7}$

At the implementation stage, the executive supplies the public goods, but it is monitored by the legislature. An exogenous proportion $\delta \in[0,1]$ of $\widetilde{\kappa}_{t}$, the expenditures approved for the provision of the public capital good, cannot be reassigned. The interpretation is that these resources represent public funds affected

\footnotetext{
${ }^{6}$ To simplify the analysis, neither the legislative electoral process nor the citizens' individual decision of entering into the political arena are modeled.

${ }^{7}$ The possibility that $L$ overrides $E$ 's veto, not considered here, is trivial to analyze. However, this is an unlikely case, since it usually requires that the majority leader $L$ in the legislature have a qualified majority to impose its criterion when $E$ vetoes an amendment.
} 
to specific ends, whose realizations are subject to the revision and control of the legislature. Thus, the executive leader can at most reassign an amount $(1-\delta) \widetilde{\kappa}_{t}$ of resources to the provision of $g_{t}$. The measure $\delta$ determines the effective limits the legislature imposes on the executive office. ${ }^{8}$

\subsection{Asymmetric information}

In each period $t \in T$, incumbents do not observe the value of $\varepsilon_{t}$ before making budget allocation decisions. This assumption simply implies that, ex-ante, they are uncertain about how well they will be able to transform government revenues into public output.

As to the electorate $V$, it does not observe neither the executive leader's most recent competence shock, $\varepsilon_{t}$, nor the allocation $\left(\gamma_{t}, \kappa_{t}\right)$ before voting. ${ }^{9}$ The only information it receives is the amount of the consumption good $g_{t}$ that is provided. Thus, incumbents have a temporary information advantage over the actual budget allocation implemented. All past competence shocks, as well as the amount of tax revenues, are common knowledge. Finally, even though voters do not observe the particular circumstances incumbents confront at a given date, they know the incentives they face and the objectives they try to achieve.

\subsection{The game}

Given the MA(1) process for competence, the infinite-horizon model described above can be broken down into a sequence of two-period sequential games, in which each election is independently analyzed. Consider one of these games, which will be referred to as $G$. Call $t$ and $t+1$ its two periods, such that $t \in T_{1}$ and $t+1 \in T_{2}$. The set of players of $G$ are the two incumbents, $E$ and $L$, the representative voter, $V$, and Nature. ${ }^{10}$

\footnotetext{
${ }^{8}$ Notice that the legislature is endowed with the power to guarantee some specific items will be supplied, but not to prevent the over-provision of other public goods. It will be clear below that incumbents confronted with electoral contests refrain from transferring resources from $g_{t}$ to $k_{t+1}$. The reason is only the provision of the more visible (consumption) goods will be effective for the incumbent's purpose of appearing talented to voters before elections.

${ }^{9}$ It is also assumed that $V$ knows two parameters of the budget process, $\bar{\gamma}$ and $\delta$. Below, we discuss qualitatively how the baseline results change if these variables of the budget process are not observed by $V$. In that case, the estimated value of $\gamma_{t}$ will be a function of the estimated values of $\bar{\gamma}$ and $\delta$.

${ }^{10}$ Two comments are in order. First, since individuals are identical, there is no loss of generality in using a single representative voter. Second, the two potential incumbents $\hat{E}(t)$ and $\hat{L}(t)$ should formally be included in the set of players. However, since these players (potentially) participate only in the last period of the game, and the optimal strategies of all incumbents at this postelectoral period are the same, the distinction between them and the original incumbents will be
} 
Let $\Gamma=[0, \tau] \subset \Re_{+}$be the set of feasible expenditures on the public consumption good. A pure strategy for $E$ in $G$ is a pair $\lambda^{E}=\left(\lambda_{t}^{E}, \lambda_{t+1}^{E}\right)$ such that, for each $s \in\{t, t+1\}, \lambda_{s}^{E}=\left(\tilde{\gamma}_{s}^{E}, d_{s}^{E}, \gamma_{s}\right)$, where ${ }^{11}$

- $\tilde{\gamma}_{s}^{E}: \Gamma \rightarrow \Gamma$ is $E$ 's budget allocation proposal, which is a function of the status quo $\bar{\gamma} \in \Gamma$;

- $d_{s}^{E}:\{0,1\} \times \Gamma \times \Gamma \rightarrow\{0,1\}$ is $E$ 's veto decision rule, which depends on $L$ 's approval or rejection of $\tilde{\gamma}_{s}^{E}$, L's amended proposal $\tilde{\gamma}_{s}^{L}$ in case of rejection (to be specified below) and $\bar{\gamma}$; and,

- $\gamma_{s}: \Gamma \times[0,1] \rightarrow \Gamma$ denotes actual expenditures on $g_{s}$, which depends on effective legislative oversight and control $\delta \in[0,1]$ and authorized expenditures $\tilde{\gamma}_{s} \in \Gamma$ (yet to be defined).

In the same way, a pure strategy for $L$ in $G$ is a pair $\lambda^{L}=\left(\lambda_{t}^{L}, \lambda_{t+1}^{L}\right)$ such that, for each $s \in\{t, t+1\}, \lambda_{s}^{L}=\left(d_{s}^{L}, \tilde{\gamma}_{s}^{L}\right)$, where

- $d_{s}^{L}: \Gamma \times \Gamma \rightarrow\{0,1\}$ is $L$ 's veto decision rule, given $\tilde{\gamma}_{s}^{E}$ and $\bar{\gamma}$; and,

- $\tilde{\gamma}_{s}^{L}: \Gamma \times[0,1] \rightarrow \Gamma\left(\tilde{\gamma}^{E}\right)$ is an amendment rule, as a function of $\bar{\gamma}$ and $\delta$, where $\Gamma\left(\tilde{\gamma}^{E}\right) \subseteq \Gamma \cup\{\emptyset\}$ represents the set of feasible amendments to $\tilde{\gamma}_{s}^{E}$. For simplicity, the analysis will focus on two extreme cases where $\Gamma\left(\tilde{\gamma}^{E}\right)$ does not depend on $\tilde{\gamma}_{s}^{E}$ : (i) Closed rule: $\Gamma\left(\tilde{\gamma}^{E}\right)=\emptyset$ and (ii) Open rule: $\Gamma\left(\tilde{\gamma}^{E}\right)=\Gamma$.

Finally, in order to decide its vote, $V$ compares the flow of payoffs expected under each of the potential executive incumbents. Let $\theta_{t}^{e} \equiv E_{t}\left[\theta_{t} \mid g_{t}\right]$ denote voters' expectations, based on observable information. In electoral period $t$ the voter behaves according to the forward-looking voting rule $\lambda^{V}: \Theta_{t} \rightarrow\{0,1\},{ }^{12}$

$$
\lambda^{V}=\{1
$$

where $\lambda^{V}=1$ represents $V$ 's decision to keep the current executive incumbent in office, while $\lambda^{V}=0$ is vote to replace it, and $v\left(\gamma_{s}, \theta_{s}\right) \equiv u\left[\theta_{s} \gamma_{s}, \theta_{s}\left(\tau-\gamma_{s}\right)\right]$ is the indirect utility function, for $s \in\{t, t+1\}$.

omitted. This simplifies the notation considerably.

${ }^{11}$ In an slight abuse of notation, $\lambda_{t+1}^{E}$ is used to denote both a (conditional on being reelected) strategy for $E$ at $t+1$ and a possible plan of action for the (potential) executive incumbent $\hat{E}(t)$. This simplification is also adopted below for $L$ 's strategies. It entails no loss of generality, because all incumbents choose the same optimal strategy in the last period of the game.

${ }^{12}$ The restriction of $\lambda^{V}$ to pure strategies (to a yes or no vote) makes sense in large populations, since it may be unrealistic to assume that voters coordinate on implementing a strategy that makes reelection random from the point of view of the executive incumbent. 
For each $j \in\{E, L, V\}$, let $\Lambda^{j}$ denote player $j$ 's set of pure strategies. A pure strategy profile in $G$ is a vector $\lambda=\left(\lambda^{E}, \lambda^{L}, \lambda^{V}\right) \in \Lambda$, where $\Lambda \equiv \prod_{j} \Lambda^{j}$. Then, player $j$ 's expected payoffs in $G$ are given by a mapping $\pi^{j}: \Lambda \times \Theta_{t} \rightarrow \Re$, such that:

$$
\begin{aligned}
& \pi^{E}\left(\lambda, \theta_{t}^{e}\right)=E_{t}\left\{\sum_{s=t}^{t+1}\left[\beta^{s-t} v\left(\gamma_{s}, \theta_{s}\right)\right]+\mu_{s}^{E} \beta \chi \mid \lambda, \theta_{t}^{e}\right\} \\
& \pi^{L}\left(\lambda, \theta_{t}^{e}\right)=E_{t}\left\{\sum_{s=t}^{t+1}\left[\beta^{s-t} v\left(\gamma_{s}, \theta_{s}\right)\right]+\mu_{s}^{L} \beta \chi \mid \lambda, \theta_{t}^{e}\right\} \\
& \pi^{V}\left(\lambda, \theta_{t}^{e}\right)=E_{t}\left\{\sum_{s=t}^{t+1}\left[\beta^{s-t} v\left(\gamma_{s}, \theta_{s}\right)\right] \mid \lambda, \theta_{t}^{e}\right\}
\end{aligned}
$$

where $\beta \in(0,1)$ is a common discount factor and $\mu_{s}^{j}$ is the probability incumbent $j$ attaches to being in office in period $s$,

$$
\mu_{s}^{E}=\{1
$$

and

$$
\mu_{s}^{L}=\{1
$$

In each period $s \in\{t, t+1\}$, the timing of events is as follows:

1. $E$ proposes $\tilde{\gamma}_{s}^{E}$ to $L$.

2. $L$ observes $\tilde{\gamma}_{s}^{E}$ and

(a) (i) If $\Gamma\left(\tilde{\gamma}^{E}\right)=\emptyset, L$ chooses whether to accept $\tilde{\gamma}_{s}^{E}$ or not, and

$$
\tilde{\gamma}_{s}=\left\{\tilde{\gamma}_{s}^{E}\right.
$$

(b) (ii) If $\Gamma\left(\tilde{\gamma}^{E}\right)=\Gamma, L$ decides whether to amend $\tilde{\gamma}_{s}^{E}$ or not. If it is modified, $E$ chooses whether to veto $\tilde{\gamma}_{s}^{L}$ or not, and

$$
\tilde{\gamma}_{s}=\left\{\tilde{\gamma}_{s}^{E}\right.
$$

3. E implements $\gamma_{s}$, which may differ from plan $\tilde{\gamma}_{s}$ if $\delta<1$, and $\kappa_{s}$ is determined residually.

4. $\varepsilon_{s}$ is realized and $g_{s}$ and $k_{s+1}$ are determined according to (3) and (4);

5. $V$ observes $g_{s}$, but not $k_{s+1}$, nor $\varepsilon_{s}$ and $\left(\gamma_{s}, \kappa_{s}\right)$; 
6. If $s=t, \hat{L}$ chooses a new legislative leader for the next political term. Simultaneously, $V$ decides whether to vote for $E$ or not. If $E$ is reelected, it stays in office for two more periods. If not, $\hat{E}$ chooses a new executive leader, whose competence at $t+1$ is determined by Nature from the probability distribution of $\varepsilon$;

7. Individuals observe $k_{s+1}$ and period $s$ ends.

Since this game is not of perfect information, the equilibrium concept used to solve it is (weak) perfect Bayesian equilibrium in pure strategies. This equilibrium concept involves an explicit description of players' beliefs, which must be statistically consistent with the strategy profile, as well as the optimality requirement that, given these beliefs, agents must choose a best response to the other players' strategies. More precisely,

Definition: A pure strategy equilibrium for $G$ is a profile of strategies $\hat{\lambda}=\left(\hat{\lambda}^{E}, \hat{\lambda}^{L}, \hat{\lambda}^{V}\right)$ and a belief for competence $\theta_{t}^{e}$, which are all common knowledge, such that, in $G$ or any continuation game of $G$,

- Given $\hat{\lambda}^{-j}$ and the specified belief $\theta_{t}^{e}$, each player $j \in\{E, L, V\}$ weakly prefers $\hat{\lambda}^{j}$ to $\lambda^{j}$, for all $\lambda^{j} \in \Lambda^{j}$.

- $\theta_{t}^{e} \equiv E_{t}\left[\theta_{t} \mid g_{t}\right]$ is determined using Bayes rule and $\hat{\lambda}$ on the equilibrium path; off the equilibrium path, it is determined by the condition that unexpectedly low values of $g_{t}$ correspond to minimum competence, while unexpectedly high values of $g_{t}$ correspond to maximum competence.

\section{Equilibrium analysis}

This section analyzes the effects of different institutional arrangements over the size of the electoral cycle in the composition of public expenditures. It starts by considering the case without elections.

\subsection{Benchmark}

Suppose no electoral contest is held. That is, assume a unique individual is randomly selected at the beginning of period $t$, after which it controls both the executive and the legislature. Let $\Delta=\left|\gamma_{t+1}-\gamma_{t}\right|$ denote the size of the electoral cycle on budget expenditures $\gamma$. 
Remark 1 If there are no elections, then every period equilibrium expenditures are given by $\gamma^{*}=\alpha \tau$ and $\kappa^{*}=(1-\alpha) \tau$. Hence, electoral cycle $\Delta^{*}=0$.

This is the social planner's solution, which is obtained in the usual way.

\subsection{One policy-maker}

Assume now an electoral contest takes place at date $t$. One can assume that only one policy-maker $I(=E=L)$ exists, or that the result of the legislative electoral process, represented by $\hat{L}(t)$, is perfectly correlated with the outcome of the presidential election. This situation corresponds to the usual situation analyzed in the literature on rational PBC, which we denote "unification of powers". Then, we have the following result: ${ }^{13}$

Proposition 1 Suppose there is unification of powers. There is a unique pure strategy equilibrium $\hat{\lambda}^{u}$ in $G$ such that $\gamma_{t+1}^{u}=\gamma^{*}, \gamma_{t}^{u}>\gamma^{*}$ is implicitly defined by the condition

$$
\left(\frac{\gamma_{t}^{u}}{\tau-\gamma_{t}^{u}}\right)^{\alpha}\left(\gamma_{t}^{u}-\alpha \tau\right)=\beta \chi \tilde{F}^{\prime},
$$

and $\lambda^{V}=1$ if and only if $\theta_{t}^{e}=g_{t} / \gamma_{t}^{e} \geq \bar{\theta}+\varepsilon_{t-1}$.

Corollary 1 There is an electoral cycle, $\Delta^{u}>0$; and $\Delta^{u}$ is strictly increasing in both $\chi$ and $\beta$.

The proofs of Proposition 1 and Corollary 1 are as follows. First of all, notice that our treatment of the infinite-horizon game as a sequence of two-period games is well-defined, since each individual game is uncorrelated with any other member of the sequence. To illustrate this, consider for example the expected utility of $V$ at the post-electoral period $t+3$. By voting rule (6), this determines $V$ 's vote at $t+2$. However, since competence follows a MA(1) process, $V$ 's expected utility at $t+3$ is not affected by $E$ 's competence at $t+1: E_{t+1}\left[\theta_{t+3} \mid \theta_{t+1}\right]=E_{t+1}\left[\theta_{t+3}\right]=\bar{\theta}$. Therefore, period $t+1$ in $G$ is independent of the continuation game. This implies $I$ has no incentives to manipulate $V$ 's perception of its competence at $t+1$ and, consequently, that actual expenditures on $g_{t+1}$ are $\gamma_{t+1}^{u}=\gamma_{t+1}^{*}$.

Consider now electoral period $t$. From voter preferences (1) and $\gamma_{t+1}^{u}$, maximization of expected utility in (6) implies that $V$ votes for $I$ if and only if the expected competency of $I$ is larger than the opposition's. Given that the only information on potential replacement is average competency, while voters' expectations about $I$ 's competency are given by $\theta_{t}^{e} \equiv E_{t}\left[\theta_{t} \mid g_{t}\right], E_{t}\left[\theta_{t+1} \mid \lambda^{V}=1\right] \geq$ $E_{t}\left[\theta_{t+1} \mid \lambda^{V}=0\right]$ if and only if $\theta_{t}^{e}-\varepsilon_{t-1} \geq \bar{\theta}$.

\footnotetext{
${ }^{13}$ The superscript $u$ stands for equilibrium values under "unification of powers".
} 
Since at election time $V$ knows $g_{t}$, but it does not observe $\varepsilon_{t}$, it has to estimate $\theta_{t}^{e}$. Let $\gamma_{t}^{e}$ be the solution, expected by $V$, of the incumbent's optimization problem at date $t .{ }^{14}$ Using equation (3) and Bayes rule, $V$ estimates $I$ 's competence by

$$
\begin{aligned}
\theta_{t}^{e} & =E_{t}\left[\theta_{t} \mid g_{t}\right]=\int_{\theta_{t} \in \Theta_{t}} \theta_{t} \tilde{F}\left(\theta_{t} \mid g_{t}\right) d \theta_{t}, \\
& =\frac{g_{t}}{\gamma_{t}^{e}} \underbrace{\int_{\theta_{t} \in \Theta_{t}} \tilde{F}\left(\theta_{t} \mid g_{t}\right) d \theta_{t}}_{=1}=\frac{g_{t}}{\gamma_{t}^{e}} .
\end{aligned}
$$

The probability $I$ attaches to being in office in period $t+1, \mu_{t+1}^{I}$, is as follows. By (3) and (14), $\theta_{t}^{e} \geq \bar{\theta}+\varepsilon_{t-1}$ if and only if $\theta_{t} \geq \frac{\left(\bar{\theta}+\varepsilon_{t-1}\right) \gamma_{t}^{e}}{\gamma_{t}}$. Using (10),

$$
\mu_{t+1}^{I}\left(\gamma_{t}\right)=1-\tilde{F}\left(\frac{\left(\bar{\theta}+\varepsilon_{t-1}\right) \gamma_{t}^{e}}{\gamma_{t}}\right)
$$

Thus, I's maximization problem at period $t$ can be written as,

$$
\max _{\gamma_{t}} E_{t}\left\{\theta_{t}\left(\gamma_{t}\right)^{\alpha}\left(\tau-\gamma_{t}\right)^{1-\alpha}+\beta \mu_{t+1}^{I} \chi\right\},
$$

subject to (15). Taken the first order condition with respect to $\gamma_{t}$, we have

$$
\left(\frac{\gamma_{t}}{\tau-\gamma_{t}}\right)^{\alpha}\left[1-\alpha\left(\frac{\tau-\gamma_{t}}{\gamma_{t}}+1\right)\right]=\frac{\beta \chi \tilde{F}^{\prime} \gamma_{t}^{e}}{\left(\gamma_{t}\right)^{2}}
$$

In equilibrium, $\gamma_{t}=\gamma_{t}^{e}$, since actual and expected decisions coincide. Denote equilibrium $\gamma_{t} \equiv \gamma_{t}^{u}$. Therefore, (17) can be re-written as

$$
\left(\frac{\gamma_{t}^{u}}{\kappa_{t}^{u}}\right)^{\alpha}\left(\gamma_{t}^{u}-\alpha \tau\right)=\beta \chi \tilde{F}^{\prime}
$$

Notice that the right hand side in (18) is positive. Thus, $\left(\gamma_{t}^{u}-\alpha \tau\right)>0$, which means $\gamma_{t}^{u}>\alpha \tau=\gamma_{t}^{*}$ and $\kappa_{t}^{u}<(1-\alpha) \tau=\kappa_{t}^{*}$. Further, in equilibrium, $\mu_{t+1}^{I}=$ $1-\tilde{F}(\bar{\theta})=\frac{1}{2}$. Finally, uniqueness of $\gamma_{t}^{u}$ follows from the strict concavity of both (15) and (16).

As to the proof of Corollary 1, the first part is immediately derived from Proposition 1 . With respect to the second part, to see that $\Delta^{u}$ is strictly increasing in $\chi$, notice first that $\partial \Delta^{u} / \partial \chi=\partial \gamma_{t}^{u} / \partial \chi$. Therefore, totally differentiating the first order condition (18) with respect to $\chi$, it follows that

$$
\frac{\partial \gamma_{t}^{u}}{\partial \chi}=\frac{\beta \tilde{F}^{\prime}}{\left(\frac{\gamma_{t}^{u}}{\tau-\gamma_{t}^{u}}\right)^{\alpha}\left[\frac{\alpha \tau\left(\gamma_{t}^{u}-\alpha \tau\right)}{\gamma_{t}^{u}\left(\tau-\gamma_{t}^{u}\right)}+1\right]}
$$

\footnotetext{
${ }^{14}$ Since $I$ does not observe its competence before choosing the expenditure composition, $\gamma_{t}^{e}$ cannot depend on $\theta_{t}$.
} 
which is strictly greater than zero. Following the same reasoning, it can be shown that

$$
\frac{\partial \gamma_{t}^{u}}{\partial \beta}=\frac{\chi \tilde{F}^{\prime}}{\left(\frac{\gamma_{t}^{u}}{\tau-\gamma_{t}^{u}}\right)^{\alpha}\left[\frac{\alpha \tau\left(\gamma_{t}^{u}-\alpha \tau\right)}{\gamma_{t}^{u}\left(\tau-\gamma_{t}^{u}\right)}+1\right]},
$$

is also positive. This complete the proof.

Thus, under the assumption of unification of powers (only one policy-maker), our model predicts optimal equilibrium policy during off-electoral periods, and public consumption expenditures above the optimal level during electoral periods. These results are pretty standard, having to do with the MA(1) nature of competency shocks.

The intuition for the result in the post-electoral period is clear. Since reputation of competence lasts only one period, there is no incentive to distort fiscal policy at $t+1$. But, why is it that the optimal allocation at date $t$ cannot be sustained in equilibrium? Ultimately, both $V$ and $I$ would be better off with budget allocation $\gamma^{*}$ instead of $\gamma^{u}$. The crucial point to understand this is to see that $I$ cannot credible compromise to follow $\gamma^{*}$ during electoral periods. If such policy were expected by $V$, then $I$ would have an incentive to exploit its discretionary power to deviate to $\gamma^{u}$, since such deviation would increase its probability of being reelected. Hence, this cannot be part of an equilibrium. In each electoral period the incumbent trades-off the efficiency cost of distorting the composition of public expenditures against a higher probability of winning the contest. Its incentive to appear competent before elections induces overspending on the more visible (consumption) good, at the expense of the less visible (investment) good. ${ }^{15}$

In models of PBC à la Lohmann, where policy choices are made before the competence shock is realized, the credibility problem depicted above is at the heart of the electoral distortion of fiscal policy. This policy bias is similar to the bias generated by credibility problems in the time consistency literature, such as the inflation bias in the Barro-Gordon model. ${ }^{16}$

Following the institutional solutions suggested by this literature, like the delegation of monetary policy to a conservative central banker, the next section will examine whether the credibility problem of our model can be alleviated by restricting the executive's capacity of unilateral moves. The reason to do this is that

\footnotetext{
${ }^{15}$ Notice that, even though the policy bias in electoral periods reduces voters' welfare, there is a positive selection effect after elections, because elections help to select candidates with aboveaverage competency for office. Hence the net effect may be positive or negative (Lohmann 1998b).

${ }^{16}$ The Barro-Gordon model assumes that commitment is achieved if policy is decided before expectations, instead of being set simultaneously or afterwards. In our model, this is not enough to achieve commitment because of asymmetric information on the actual budget allocation: in electoral period $t$, high $g_{t}$ may be due either to high competency, or to an electoral manipulation of budget allocation that implies low $k_{t+1}$ in the future.
} 
the lack of credibility and the electoral bias are in fact produced by concentration of powers, which allows the all-powerful executive to choose any policy it desires. Instead, when there exists separation of powers, we will show that appropriate checks and balances, by requiring joint agreement in the policy-making process, provide the kind of commitment device that allows $E$ to credible compromise to optimal policies. Therefore, it could be that, under this institutional arrangement, all players are made better off, including the executive incumbent.

\subsection{Two policy-makers}

This section incorporates a second policy-maker, the legislature, into the model, as well as the institutional structure of checks and balances discussed in Section 2. The main purpose is to analyze how the results of the previous section change after these modifications are introduced.

We first consider the case of perfect compliance with the budget law, before introducing the consequences of imperfect compliance. The point of this distinction is that what matters for PBC is not nominal checks and balances, but rather the effective checks and balances. Two variants of the system of checks and balances are considered in each case, depending on whether $\Gamma\left(\tilde{\gamma}^{E}\right)=\emptyset$ or $\Gamma\left(\tilde{\gamma}^{E}\right)=\Gamma$.

\subsubsection{Perfect compliance}

This case corresponds to $\delta=1$, and represents a situation where there is perfect legislative oversight and no enforcement problems. In other words, it is the case in which the budget law approved through the budgetary process is the policy implemented by the executive.

Closed rule: Assume no amendments can be made to the executive's proposal. That is, following the jargon of the legislative bargaining literature, suppose there exists a closed rule, so that the legislature faces each period a take-it-or-leave-it allocation proposal, with the rejection followed by the exogenous reversion point $(\bar{\gamma}, \bar{\kappa})$.

For $j \in\{E, L\}$, let $\tilde{\pi}^{j}(\cdot)$ denote player $j$ 's policy preferences over $\Gamma$, with ideal policy $\gamma^{j}=\arg \max \tilde{\pi}^{j}(\gamma) \cdot{ }^{17}$ Define the function $r^{j}: \Gamma \rightarrow \Gamma$ as follows: $\forall \gamma^{\prime} \in\left[0, \gamma^{j}\right]$, set $r^{j}\left(\gamma^{\prime}\right)=\gamma^{\prime \prime}$ if there exists $\gamma^{\prime \prime} \in\left[\gamma^{j}, \tau\right]$ such that $\tilde{\pi}^{j}\left(\gamma^{\prime}\right)=$ $\tilde{\pi}^{j}\left(\gamma^{\prime \prime}\right)$, and $r^{j}\left(\gamma^{\prime}\right)=\tau$ otherwise. Similarly, $\forall \gamma^{\prime} \in\left[\gamma^{j}, \tau\right]$, fix $r^{j}\left(\gamma^{\prime}\right)=\gamma^{\prime \prime}$ if

\footnotetext{
${ }^{17}$ The ideal policy of each incumbent is the policy it would choose if it were not constrained by the requirement that its proposal has to be approved by the other policy-maker.
} 
there exists $\gamma^{\prime \prime} \in\left[0, \gamma^{j}\right]$ such that $\tilde{\pi}^{j}\left(\gamma^{\prime}\right)=\tilde{\pi}^{j}\left(\gamma^{\prime \prime}\right)$, and $r^{j}\left(\gamma^{\prime}\right)=0$ otherwise. Then, we have the following result: ${ }^{18}$

Proposition 2 Suppose there is separation of powers and the legislature cannot amend the executive's proposal. With perfect budgetary compliance, there exists a unique pure strategy equilibrium $\hat{\lambda}^{s}$ in $G$ such that $d_{t+1}^{L, s}=d_{t}^{L, s}=1, \tilde{\gamma}_{t+1}^{E, s}=$ $\gamma_{t+1}^{s}=\gamma^{*}$,

$$
\gamma_{t}^{s}=\tilde{\gamma}_{t}^{E, s}= \begin{cases}\max \left\{\bar{\gamma}, r^{L}(\bar{\gamma})\right\} & \text { if } \bar{\gamma} \in\left(r^{L}\left(\gamma^{u}\right), \gamma^{u}\right) \\ \gamma^{u} & \text { otherwise }\end{cases}
$$

and $\lambda^{V}=1$ if and only if $\theta_{t}^{e}=g_{t} / \gamma_{t}^{e} \geq \bar{\theta}+\varepsilon_{t-1}$.

Corollary 2 Except in the case where $\bar{\gamma}=\gamma^{*}$, there is an electoral cycle with the following properties:

1. If $\bar{\gamma} \in\left(r^{L}\left(\gamma^{u}\right), \gamma^{u}\right)$, then $\Delta^{*} \leq \Delta^{s}<\Delta^{u} ; 19$

2. If $\bar{\gamma} \in\left[0, r^{L}\left(\gamma^{u}\right)\right] \cup\left[\gamma^{u}, \tau\right]$, then $\Delta^{s}=\Delta^{u}$.

To prove Proposition 2, consider first the post-electoral period $t+1$. Following the argument applied in Proposition 1, it is immediate to note that the incumbents implement their common most-preferred policy $\gamma^{*}$. No agent can be made better off by unilateral deviations.

Going back to the electoral period $t$, the problem for $V$ is still to estimate the competence of $E, E_{t}\left[\theta_{t} \mid g_{t}\right]$, after having observed $g_{t}$. As in the previous section, for the expected equilibrium policy $\gamma_{t}^{e}, \theta_{t}^{e}=g_{t} / \gamma_{t}^{e}$. Therefore, $\mu_{t+1}^{E}$ has the same form as (15).

However, $\gamma_{t}$ is now determined in a non-trivial bargaining process between the executive and the legislature, instead of being unilaterally set by $E$. Under the closed rule, $E$ has maximum power in the bargaining game. Therefore, it can be conjectured that $L$ will be nailed to its status quo payoff. Based on this conjecture, the process is solved in the following way. Consider first incumbents' preferences over $\gamma_{t}$. For each $j \in\{E, L\}$, let $\tilde{\pi}^{j}: \Gamma \rightarrow \Re$ denote player $j$ 's payoff as a function of $\gamma_{t}$ :

$$
\begin{aligned}
\tilde{\pi}^{j}\left(\gamma_{t}\right) & =\pi^{j}\left(\gamma_{t} \mid \hat{\lambda}_{t+1}^{s}\right) \\
& =E_{t}\left\{v\left(\gamma_{t}, \theta_{t}\right)+\beta\left[v\left(\gamma^{*}, \theta_{t+1}\right)+\mu_{t+1}^{j} \chi\right]\right\} .
\end{aligned}
$$

\footnotetext{
${ }^{18}$ The superscript $s$ stands for equilibrium values under "separation of powers".

${ }^{19}$ Notice that $\Delta^{s}=\Delta^{*}$ only if $\bar{\gamma}=\gamma^{*}$.
} 
It is immediate to see that $\tilde{\pi}^{j}$ is single-peaked on $\Gamma$, with ideal policies $\gamma^{L}=\gamma^{*}$ and $\gamma^{E}=\gamma^{u}{ }^{20}$

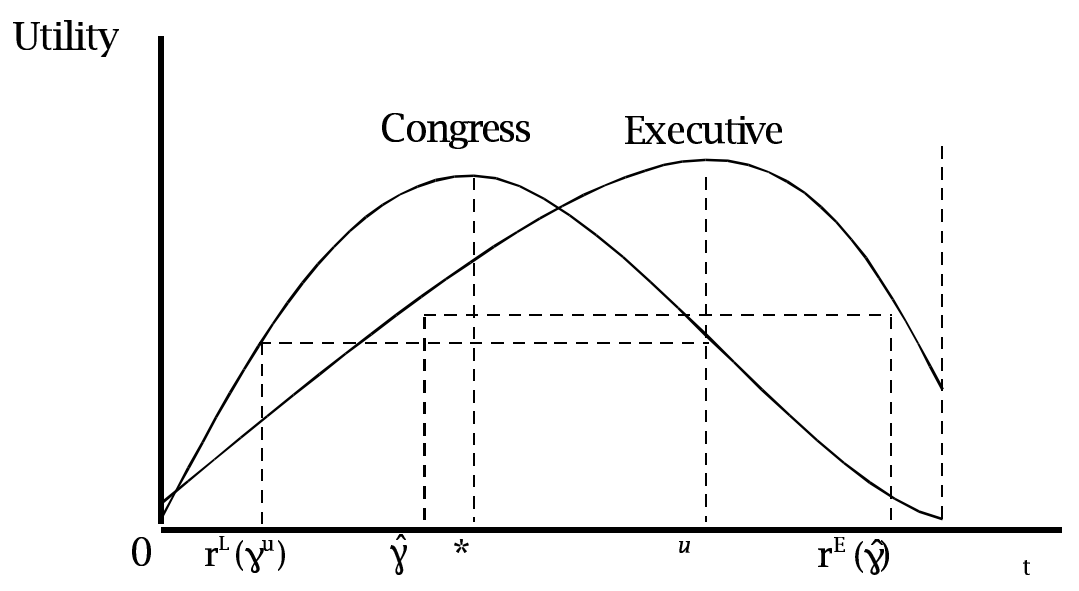

Figure 1: Incumbents' Preferencesover t

In order to pass a proposal $\tilde{\gamma}_{t}^{E}, E$ has to guarantee $L$ at least its reservation payoff $\tilde{\pi}^{L}(\bar{\gamma})$, to persuade it not to reject $\tilde{\gamma}_{t}^{E}$. That is, the executive's proposal has to satisfy the incentive constraint

$$
\tilde{\pi}^{L}\left(\tilde{\gamma}_{t}^{E}\right) \geq \tilde{\pi}^{L}(\bar{\gamma})
$$

Therefore, the problem of $E$ at date $t$ is to choose $\tilde{\gamma}_{t}^{E}$ in order to maximize $\tilde{\pi}^{E}\left(\gamma_{t}\right)$ subject to (20) and (15). Looking at Figure 1, it is clear that only two cases are possible. If $\bar{\gamma} \in\left[0, r^{L}\left(\gamma^{u}\right)\right] \cup\left[\gamma^{u}, \tau\right]$, then (20) is not binding, since $\tilde{\pi}^{L}\left(\gamma^{u}\right)>$ $\tilde{\pi}^{L}(\bar{\gamma})$ for all $\bar{\gamma} \neq \gamma^{u}$. That is, the reversion outcome is too low or too high, so that $L$ is unable to affect the equilibrium budgetary policy $\tilde{\gamma}_{t}^{s}$, by triggering $E$ to refuse its proposal. $V$ anticipates this and expects $E$ will obtain in equilibrium authorized expenditures $\tilde{\gamma}_{t}^{s}=\gamma^{u}$. Therefore, the same reasoning of Section 3.2 applies.

On the other hand, if $\bar{\gamma} \in\left(r^{L}\left(\gamma^{u}\right), \gamma^{u}\right)$, then $\tilde{\gamma}_{t}^{s}$ will be above $\gamma^{*}$, but below $\gamma^{u}$ (except, of course, in case when $\bar{\gamma}=\gamma^{*}$ ). Concretely, since $L$ would reject any other proposal that violates (20), $E$ ties $L$ to its status quo payoff by proposing

\footnotetext{
${ }^{20}$ Single-peakedness follows from the strict concavity of $E_{t}\left[v\left(\gamma_{t}, \theta_{t}\right)\right]$ and $\mu_{t+1}^{E}\left(\gamma_{t}\right)$. We are considering policy actions that are not constrained by the requirement that they be accepted by the other policy-maker. While $L$ cannot affect its probability of reelection, $E$ takes into account the trade-off between the probability of reelection and the current cyclical distortion.
} 
$\tilde{\gamma}_{t}^{E}=\max \left\{\bar{\gamma}, r^{L}(\bar{\gamma})\right\}$. It will never offer more than that, since this proposal makes $L$ indifferent between either accepting it or rejecting it and getting the default payoff. That is, $L$ could not be strictly better off by rejection. Hence, $d_{t}^{L}=1$.

In both cases, rationality of expectations implies the optimal solution of $E$ coincides with $V$ 's expected equilibrium policy. Finally, notice that $\tilde{\gamma}_{t}^{E}$ will be lower, the closer $\bar{\gamma}$ is to $\gamma^{*}$. In effect, $\frac{\partial \tilde{\gamma}_{t}^{E}}{\partial \bar{\gamma}} \geq 0$ for all $\bar{\gamma} \geq \gamma^{*}$ and $\frac{\partial \tilde{\gamma}_{t}^{E}}{\partial \bar{\gamma}}<0$ for $\bar{\gamma}<\gamma^{*}$.

In words, Proposition 2 says that separation of powers moderates electoral cycles for intermediate reversion levels (i.e., for $\bar{\gamma} \in\left(r^{L}\left(\gamma^{u}\right), \gamma^{u}\right)$ ), but not for extreme levels, where cycles are just like under unification of powers.

Open rule: Suppose now the legislature can introduce any amendment into the executive's proposal, but the executive has veto power over it. Under this institutional structure, the role of each incumbent is in fact reversed. That is, $L$ becomes the actual agenda-setter, while $E$ reduces to a veto player. The main result is the following:

Proposition 3 Suppose there is separation of powers and the legislature can introduce any amendment into the executive's proposal. With perfect budgetary compliance, there exists a unique pure strategy equilibrium $\hat{\lambda}^{s}$ in $G$ such that $d_{t+1}^{L, s}=d_{t}^{L, s}=1, \tilde{\gamma}_{t+1}^{E, s}=\gamma_{t+1}^{s}=\gamma^{*}$,

$$
\gamma_{t}^{s}=\tilde{\gamma}_{t}^{E, s}= \begin{cases}\min \left\{\bar{\gamma}, r^{E}(\bar{\gamma})\right\} & \text { if } \bar{\gamma} \in\left(\gamma^{*}, r^{E}\left(\gamma^{*}\right)\right), \\ \gamma^{*} & \text { otherwise, }\end{cases}
$$

and $\lambda^{V}=1$ if and only if $\theta_{t}^{e}=g_{t} / \gamma_{t}^{u} \geq \bar{\theta}$.

Corollary 3 Except in the case where $\bar{\gamma}=\gamma_{t}^{u}$, the electoral cycle is dampened or eliminated by separation of powers:

1. If $\bar{\gamma} \in\left[0, \gamma^{*}\right] \cup\left[r^{E}\left(\gamma^{*}\right), \tau\right]$, then $\Delta^{s}=\Delta^{*}$;

2. If $\bar{\gamma} \in\left(\gamma^{*}, r^{E}\left(\gamma^{*}\right)\right)$, then $\Delta^{*}<\Delta^{s} \leq \Delta^{u}$.

To derive Proposition 3, the analysis is similar to Proposition 2. The equilibrium at the post-electoral period $t+1$ and the optimal response of $V$ to the observation of $g_{t}$ are exactly the same.

With respect to the bargaining process carried out at period $t$, the only difference is who has the effective power to make final offers. Here the actual agendasetter is the legislative leader, instead of the executive incumbent. It will be clear 
below that this reduces considerably the electoral distortion on $\gamma_{t}$, compared with a closed rule, since it curtails $E$ 's power over the budget composition.

For $\bar{\gamma} \in\left[0, \gamma^{*}\right] \cup\left[r^{E}\left(\gamma^{*}\right), \tau\right]$, the legislature's leader would amend any executive proposal $\tilde{\gamma}_{t}^{E} \neq \gamma^{*}$ by setting $\tilde{\gamma}_{t}^{L}=\gamma^{*}$. This amendment satisfies the incentive constraint $\tilde{\pi}^{E}\left(\tilde{\gamma}_{t}^{L}\right) \geq \tilde{\pi}^{E}(\bar{\gamma})$ (see Figure 1). Therefore, it cannot be vetoed by $E$. Understanding this, $E$ weakly prefers to make such an offer rather than to propose a different spending level and lose approval in the legislature.

A similar reasoning can be made if $\bar{\gamma} \in\left(\gamma^{*}, r^{E}\left(\gamma^{*}\right)\right)$. However, in this case $\gamma^{*}$ does not satisfy the incentive constraint of $E$. That is, $\tilde{\pi}^{E}\left(\gamma^{*}\right)<\tilde{\pi}^{E}(\bar{\gamma})$. Therefore, $L$ cannot achieve its ideal policy $\gamma^{*}$. Nevertheless, following the logic of the agenda setter, $L$ restricts player $E$ to its reservation utility, by amending any proposal $\tilde{\gamma}_{t}^{E} \neq \min \left\{\bar{\gamma}, r^{E}(\bar{\gamma})\right\}$. Hence, this policy is proposed in equilibrium and $\Delta^{*}<\Delta^{s} \leq \Delta^{u}$, being $\Delta^{s}=\Delta^{u}$ only if $\bar{\gamma}=\gamma^{u}$.

In words, Proposition 3 says that, when there exists open rule, separation of powers completely eliminates the electoral cycles on $\gamma_{t}$ for low and high reversion levels. On the contrary, for intermediate values of $\bar{\gamma}$, the electoral cycle in public consumption expenditures cannot be eliminated, but its magnitude is reduced.

Notice that for low and high values of $\bar{\gamma}$, the results with and without amendments are exactly the opposite. While the former provides the first best allocation, the second supplies the same predictions as unification of powers. The explanation for this is based on who is the actual veto player in each case, and by the fact that the veto player has greatest power when the reversion policy is very near its most-preferred policy.

Figure 2 illustrates Proposition 2 and 3 for different status quo. In the case of closed rule, $\tilde{\gamma}_{t}^{s}$ starts at $\gamma^{u}$, for $\bar{\gamma}=0$, then it eventually starts falling, reaching $\gamma^{*}$ as $\bar{\gamma}$ approaches $\gamma^{*}$, and then it starts rising again to $\gamma^{u}$. The graph has the inverse shape in the case of open rule, starting at $\gamma^{*}$, then rising towards $\gamma^{u}$, and reaching it when $\bar{\gamma}=\gamma^{u}$, before starting to fall again. This behavior of $\tilde{\gamma}_{t}^{s}$ explains the opposite results obtained under closed and open rule. 


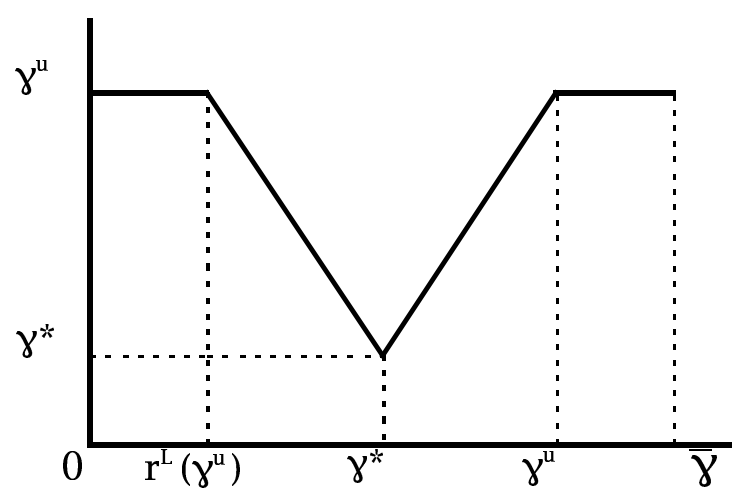

(a) Closedrule

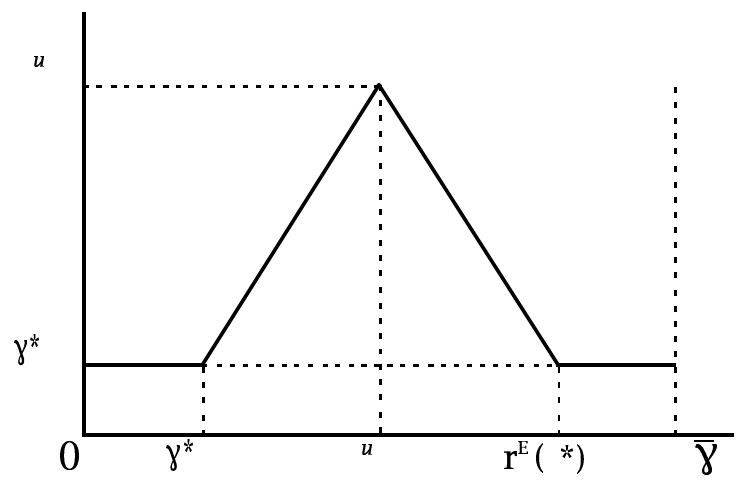

(b) Openrule

Figure2: Authorizedexpenditures

\subsubsection{Imperfect compliance}

We analyze in this section the general case $\delta \in[0,1]$, allowing for the existence of either imperfect oversight or enforcement of the budget law or both. This captures the situation where the policy approved through the budgetary process is not necessarily the policy implemented by the executive.

Closed rule: Imperfect compliance at the implementation stage makes actual electoral expenditures $\gamma_{t}^{s}$ greater than approved ones $\tilde{\gamma}_{t}^{s}$. The legislature takes this into account in the budget process, so this breaks the indifference of $L$ in Proposition 2 between $r^{L}(\bar{\gamma})$ and $\bar{\gamma}$. 
Proposition 4 If there is separation of powers and closed rule, then there exists a unique pure strategy equilibrium $\hat{\lambda}^{s}$ in $G$ such that $d_{t+1}^{L, s}=d_{t}^{L, s}=1, \tilde{\gamma}_{t+1}^{E, s}=$ $\gamma_{t+1}^{s}=\gamma^{*}$,

$$
\begin{aligned}
\tilde{\gamma}_{t}^{E, s} & =\left\{\begin{array}{cc}
\bar{\gamma} & \text { if } \bar{\gamma} \in\left(r^{L}\left(\gamma^{u}\right), \gamma^{u}\right), \\
\gamma^{u} & \text { otherwise, }
\end{array}\right. \\
\gamma_{t}^{s} & =\min \left\{\gamma^{u}, \tau-\delta\left[\tau-\tilde{\gamma}_{t}^{s}\right]\right\},
\end{aligned}
$$

and $\lambda^{V}=1$ if and only if $\theta_{t}^{e}=g_{t} / \gamma_{t}^{e} \geq \bar{\theta}^{21}$

Let $\delta^{\text {crit }}(\bar{\gamma}) \equiv \frac{\tau-\gamma^{u}}{\tau-\tilde{\gamma}^{s}(\bar{\gamma})}$ be the critical level of compliance that makes the first term of the right hand side of (23) equal to the second.

Corollary 4 Electoral cycles depend on the status quo and the degree of compliance:

1. If $\delta>\delta^{\text {crit }}(\bar{\gamma})$ and $\bar{\gamma} \in\left(r^{L}\left(\gamma^{u}\right), \gamma^{u}\right)$, then $\Delta^{*} \leq \Delta^{s}(\bar{\gamma}, \delta)<\Delta^{u}$;

2. If either $\delta \leq \delta^{\text {crit }}(\bar{\gamma})$ or $\bar{\gamma} \in\left[0, r^{L}\left(\gamma^{u}\right)\right] \cup\left[\gamma^{u}, \tau\right]$, then $\Delta^{s}(\bar{\gamma}, \delta)=\Delta^{u}$;

3. Given $\bar{\gamma} \in[0, \tau], \Delta^{s}(\bar{\gamma}, \delta)$ is non-increasing in $\delta \in[0,1)$.

Looking at (23), if $\delta=1$, then $\gamma_{t}^{s}=\tilde{\gamma}_{t}^{s}$. As $\delta$ falls, it is clear that $\gamma_{t}^{s}$ approaches $\gamma_{t}^{u}$, reaching $\gamma_{t}^{u}$ at the critical value $\delta^{\text {crit }}(\bar{\gamma})$, and staying there for lower values of $\delta$.

The legislature foresees that the executive will try to divert budgetary resources at the implementation stage. For $\delta>\delta^{c r i t}(\bar{\gamma})$ and $\bar{\gamma}<r^{L}(\bar{\gamma}), \bar{\gamma} \in$ $\left(r^{L}\left(\gamma^{u}\right), \gamma^{u}\right), L$ will no longer be indifferent between $\bar{\gamma}$ and $r^{L}(\bar{\gamma})$, since it knows that at the implementation stage $E$ will reallocate a part $1-\delta$ of any approved budget to visible expenditure. $L$ will prefer to restrict $E$ to the lower level $\bar{\gamma}$ of spending on visible goods. Note that spending will always be below the case of unification of powers, i.e. $\gamma_{t}^{s}<\gamma_{t}^{u}$.

Figure 3 below shows the shape of $\gamma_{t}^{s}$ as a function of $\delta$ :

\footnotetext{
${ }^{21}$ The proof of Proposition 4 is similar to Proposition 2. The only difference is that in this case $V$ also anticipates the use of discretion at the implementation stage. Therefore, the actual spending on $g_{t}$ moves closer to $\gamma^{u}$.
} 


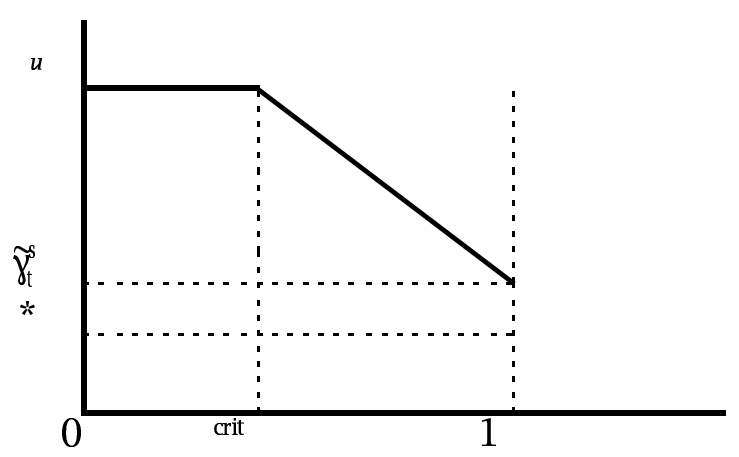

(a) $\bar{\gamma}\left(r^{\mathrm{L}}\left(\gamma^{\mathrm{u}}\right), \gamma^{\mathrm{u}}\right)$

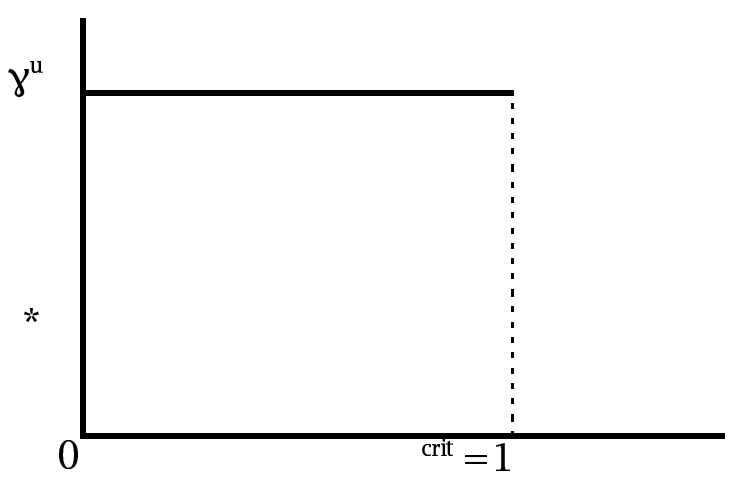

(b) $\bar{\gamma} \quad\left[0, \mathrm{r}^{\mathrm{L}}\left(\gamma^{\mathrm{u}}\right)\right] \quad\left[\gamma^{\mathrm{u}}, \mathrm{T}\right]$

\section{Figure 3: Actual expenditureunder closedrule}

For a status quo $\bar{\gamma} \in\left(r^{L}\left(\gamma^{u}\right), \gamma^{u}\right)$, Figure 3a shows that $\gamma_{t}^{s}$ coincides with $E$ 's ideal policy for $\delta \leq \delta^{\text {crit }}(\bar{\gamma})$. For $\delta>\delta^{\text {crit }}(\bar{\gamma}), \gamma_{t}^{s}$ decreases monotonically as $\delta$ rises, reaching $\tilde{\gamma}_{t}^{s}$ when $\delta=1$. Unlike Proposition 2, it reaches $\gamma^{*}$ not only for the non-generic case $\bar{\gamma}=\gamma^{*}$, but also for the $\bar{\gamma} \in\left(r^{L}\left(\gamma^{u}\right), \gamma^{*}\right)$. Indeed, in this range there can be underspending on visible public goods in election years. ${ }^{22}$ On the other hand, for $\bar{\gamma} \in\left[0, r^{L}\left(\gamma^{u}\right)\right] \cup\left[\gamma^{u}, \tau\right]$, Figure $3 \mathrm{~b}$ shows that $\gamma_{t}^{s}$ is completely insensitive to the value of $\delta$.

This discussion is formally summarized in Corollary 4. Note that point 3 of Corollary 4 means that, for a given $\bar{\gamma}$, the existence of discretion at the implemen-

\footnotetext{
${ }^{22}$ For $\delta=1, \Delta^{s}(\bar{\gamma}, \delta)=\Delta^{*}$ only if $\bar{\gamma}=\gamma^{*}$. For $1>\delta>\delta^{\text {crit }}(\bar{\gamma})$, there is $\bar{\gamma}<\gamma^{*}$ such that the effects of both parameters just cancel out, so $\Delta^{s}(\bar{\gamma}, \delta)=\Delta^{*}$ too.
} 
tation stage reduces the moderating influence of the legislature in electoral periods. This does not mean that imperfect compliance always leads to a larger cycical distortion than perfect compliance, because there is a discontinuity at $\delta=1$ in the approved budgets. As compliance falls infinitesimally, for $\bar{\gamma} \in\left(r^{L}\left(\gamma^{u}\right), \gamma^{*}\right), L$ strictly prefers the status quo $\bar{\gamma}$. The end-result may be a smaller cycle (even optimal policy) compared to perfect compliance.

Open rule: As to the case of open rule, we have the following:

Proposition 5 If there is separation of powers and open rule, there exists a unique pure strategy equilibrium $\hat{\lambda}^{s}$ in $G$ such that $d_{t+1}^{L, s}=d_{t}^{L, s}=1, \tilde{\gamma}_{t+1}^{E, s}=\gamma_{t+1}^{s}=\gamma^{*}$,

$$
\begin{aligned}
\tilde{\gamma}_{t}^{E, s} & = \begin{cases}\min \left\{\bar{\gamma}, r^{E}(\bar{\gamma})\right\} & \text { if } \bar{\gamma} \in\left(\widehat{\gamma}, r^{E}(\widehat{\gamma})\right), \\
\widehat{\gamma} & \text { otherwise, }\end{cases} \\
\gamma_{t}^{s} & =\min \left\{\gamma_{t}^{u}, \tau-\delta\left[\tau-\tilde{\gamma}_{t}^{s}\right]\right\},
\end{aligned}
$$

and $\lambda^{V}=1$ if and only if $\theta_{t}^{e}=g_{t} / \gamma_{t}^{u} \geq \bar{\theta}$, where $\widehat{\gamma}=\max \left\{0, \frac{\gamma^{*}-(1-\delta) \tau}{\delta}\right\}$.

Corollary 5 Electoral cycles depend on the status quo and the degree of compliance:

1. If either $\delta>1-\alpha$ and $\bar{\gamma} \in[0, \widehat{\gamma}] \cup\left[r^{E}(\widehat{\gamma}), \tau\right]$, or $\delta=1-\alpha$ and $\bar{\gamma} \in\{0, \tau\}$, then $\Delta^{s}(\bar{\gamma}, \delta)=\Delta^{*}$;

2. If either $\delta<1-\alpha$ or $\bar{\gamma} \in\left(\widehat{\gamma}, r^{E}(\widehat{\gamma})\right)$, then $\Delta^{*}<\Delta^{s}(\bar{\gamma}, \delta) \leq \Delta^{u}$;

3. Given $\bar{\gamma} \in[0, \tau], \Delta^{s}(\bar{\gamma}, \delta)$ is non-increasing in $\delta$.

To derive Proposition 5, we must take into account that the legislature foresees that the executive will try to divert budgetary resources at the implementation stage. For any level of authorized expenditures $\tilde{\gamma}_{t}$, the policy implemented will be $\gamma_{t}=\min \left\{\gamma_{t}^{u}, \tau-\delta\left[\tau-\tilde{\gamma}_{t}^{s}\right]\right\}$. That is, $E$ will set $\gamma_{t}$ at its most-preferred policy or, if this were not possible, it will use at the implementation the maximum degree of discretion to achieve an alternative as close as possible to $\gamma^{u}$.

For a given value of $\delta$, let $\widehat{\gamma}$ be implicitly defined by the following condition: $\tau-\delta[\tau-\hat{\gamma}]=\gamma^{*}$; or set it equal to zero if $\gamma^{*}<(1-\delta) \tau$. That is, let $\widehat{\gamma}=$ $\max \left\{0, \frac{\gamma^{*}-(1-\delta) \tau}{\delta}\right\}$. It is clear that $\widehat{\gamma}>0$ if and only if $\delta>1-\alpha$, and $\widehat{\gamma}=0$ when $\delta \leq 1-\alpha$.

For $\bar{\delta}>1-\alpha$ and $\bar{\gamma} \in[0, \hat{\gamma}] \cup\left[r^{E}(\widehat{\gamma}), \tau\right]$, the legislative leader would amend any executive proposal $\tilde{\gamma}_{t}^{E} \neq \hat{\gamma}$ by setting $\tilde{\gamma}_{t}^{L}=\widehat{\gamma}$. As in Proposition 3, this 
amendment satisfies the incentive constraint $\tilde{\pi}^{E}\left(\tilde{\gamma}_{t}^{L}\right) \geq \tilde{\pi}^{E}(\bar{\gamma})$ (see Figure 1). By definition, $\widehat{\gamma}$ ensures the legislature its ideal policy $\gamma^{*}$ is realized. The same happens if $\delta=1-\alpha$ and $\bar{\gamma} \in\{0, \tau\}$.

On the other hand, if $\delta<1-\alpha$, there is a corner solution with $\widehat{\gamma}=0$. In this case, $\hat{\gamma}$ does not satisfy the incentive constraint of $E$ for $\bar{\gamma} \in(0, \tau)$. That is, $\tilde{\pi}^{E}(\widehat{\gamma})<\tilde{\pi}^{E}(\bar{\gamma})$. Therefore, $L$ can at most restrict player $E$ to its reservation utility, by amending any proposal $\tilde{\gamma}_{t}^{E} \neq \min \left\{\bar{\gamma}, r^{E}(\bar{\gamma})\right\}$. Note that for $\bar{\gamma} \in$ $\{0, \tau\}$, the proposal will also be $\tilde{\gamma}_{t}^{E}=\min \left\{\bar{\gamma}, r^{E}(\bar{\gamma})\right\}$. Therefore, for any level of authorized expenditures $\tilde{\gamma}_{t}^{s}$, it follows that $\gamma_{t}^{s}>\gamma^{*}$. Furthermore, for $\delta \leq\left(\tau-\gamma_{t}^{u}\right) / \tau, \gamma_{t}^{s}=\gamma^{u}$, so $\Delta^{s}(\bar{\gamma}, \delta)=\Delta^{u}$. Therefore, $\Delta^{*}<\Delta^{s}(\bar{\gamma}, \delta) \leq \Delta^{u}$.

Finally, for $\bar{\gamma} \in\left(\widehat{\gamma}, r^{E}(\widehat{\gamma})\right)$, by Proposition 3 we know that $\tilde{\gamma}_{t}^{E}=$ $\min \left\{\bar{\gamma}, r^{E}(\bar{\gamma})\right\}$. And by analysis above, $\gamma_{t}^{s}$ increases as $\delta$ falls, being $\gamma_{t}^{s}=\gamma_{t}^{u}$ only if either $\delta \leq\left(\tau-\gamma_{t}^{u}\right) / \tau$ or $\bar{\gamma}=\gamma^{u}$ (see Figure 4).

Comparing Propositions 3 and 5, one can see that the moderating force of division of power, when there exists agenda-setting authority and open rule, decreases if the executive enjoys more lee-way at the implementation stage. 


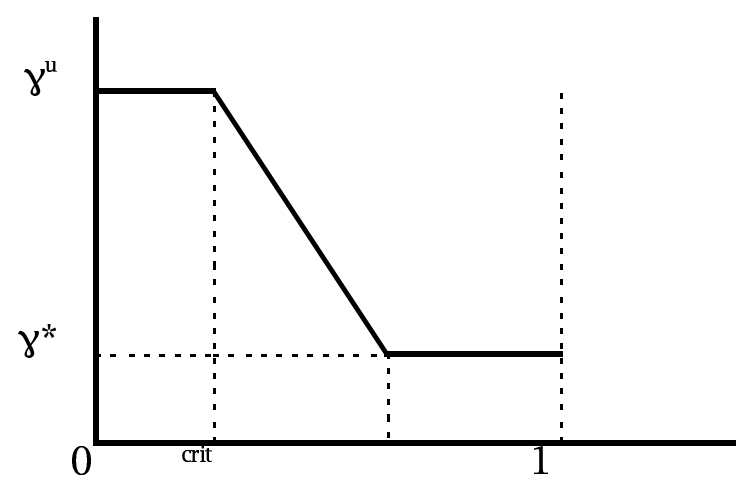

(a) $\bar{\gamma}[0, \hat{\gamma}] \quad\left[\mathrm{r}^{\mathrm{E}}(\hat{\gamma}), \mathrm{T}\right]$

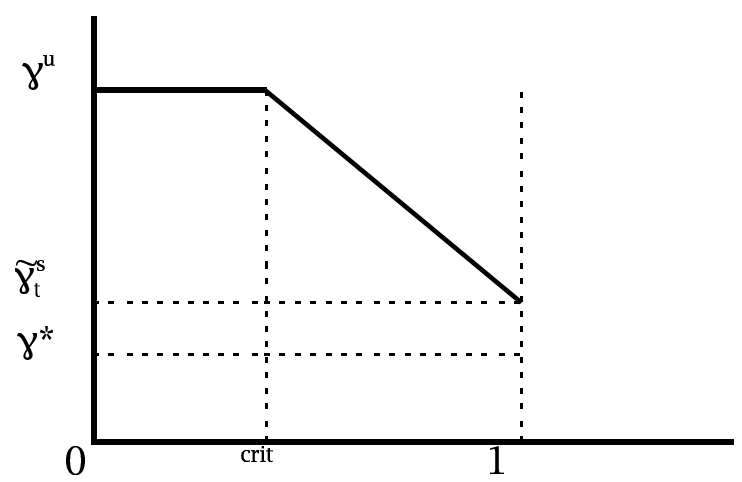

(b) $-\left(*, r^{E}(*)\right)$

Figure 4: Actual expenditure under openrule

\section{Conclusion}

In this paper we analyze a model of $\mathrm{PBC}$ with asymmetric information on the actual budget allocation. Under the standard assumption of unification of powers, the model predicts optimal equilibrium policy during off-electoral periods, but not just ahead of the elections. Policy distortions in the composition of government spending occur just before elections because the incumbent's incentive to appear 
competent during these periods induces overspending in the public consumption good (the more visible good), while simultaneously reduces the spending on the public capital good below the socially optimal level.

The fact that the executive incumbent is unable to credible compromise to the optimal allocation policy is at the heart of these electoral distortions. Furthermore, it turns out that this problem is in fact generated by concentration of powers, which allows the executive to choose any policy it desires. Instead, when there exists separation of powers, appropriate checks and balances work as a commitment device that reduces the size of political fiscal cycles, making all players better off (included the executive incumbent). This moderating force depends on the details of the bargaining game, namely the status quo location, the actual agenda-setting authority and the degree of compliance with the budget law.

Even though we do not consider signaling models of PBC à la Rogoff, it should be expected that separation of powers affect electoral fiscal cycles in a similar way. ${ }^{23}$ The legislature basically tries to avoid distortions in the allocation of budget resources. This should reduce the electoral distortions of fiscal policy, preserving the signaling role of the provision of public goods.

What may change the results is lifting the assumption that the legislature has no electoral stakes. In this regard, our case is the best scenario where the legislature controls the executive to try to assure the socially optimal policy is followed. Our model might be extended to study the role of divided goverment in presidential systems, as well as coalition governments in parlimentary systems. For instance, Alesina and Rosenthal (1995) show how divided government is a tool to moderate the executive in a presidential system. A similar logic may apply in an opportunistic framework, where an opposition legislature may play a special role in moderating cycles.

Finally, our model of PBC under separation of powers could also be employed to understand how the incumbent chooses among different fiscal instruments or why it uses some of them more frequently in some countries than in others. ${ }^{24}$ Even though the fiscal policy includes several items, like taxes, expenditure composition

\footnotetext{
${ }^{23}$ Notice that in models of PBC à la Rogoff, the timing of events is reversed in relation to Lohmann. That is, the incumbent observes its competence before choosing the per-period policy, not afterwards. However, the informativeness of the signal is not larger in equilibrium, since there is a separating equilibrium with both types of models. Nevertheless, the Rogoff timing brings in an extra complication. The signal depends on the incumbents type, something that is not required to explain the policy bias in electoral periods. Moreover, this is also an unappealing feature, since it implies that competent incumbents distort the most, while the utterly incompetent incumbents do not.

${ }^{24}$ For instance, tax cuts before elections seems to be more frequent in OECD countries, while changes of the expenditure composition and budget deficits are usually observed in Latin American countries. For more on that, see for example Block (2002), Persson and Tabellini (2002) and Shi and Svensson (2002a, 2002b).
} 
and debt, there is no general model of rational PBC that explains how politicians choose between these instruments. Following the logic of our model, it should be expected that institutional details play an important role in the selection. This is because the executive should manipulate those fiscal instruments where it has greater agenda-setting authority. It is left for a future research to formally explore this conjecture, as well as its empirical validity.

\section{References}

[1] Alesina, A. and R. Perotti. (1995). The political economy of budget deficits. IMF Staff Papers (March): 1-37.

[2] Alesina, A. and H. Rosenthal. (1995). Partisan Politics, Divided Government and the Economy. Cambridge: Cambridge University Press.

[3] Alesina, A., Hausmann, R., Hommes and E. Stein. (1999). Budget institutions and fiscal performance in Latin America. Journal of Development Economics 59: 253-273.

[4] Brender, A. and A. Drazen. (2003). Where does the political budget cycle really come from? CEPR Discussion Paper 4049.

[5] Block, S. (2002). Elections, electoral competitiveness, and political budget cycles in developing countries. Working Paper 78, Center of International Development, Harvard University.

[6] Drazen, A. (2000). Political Economy in Macroeconomics. Princeton, NJ: Princeton University Press.

[7] Drazen, A. (2001). Laying low during elections: Political pressure and monetary accommodation. Mimeo, University of Maryland.

[8] Gonzalez, M. (2000). On elections, democracy and macroeconomic policy cycles. PhD dissertation, Princeton University.

[9] Gonzalez, M. (2002). Do changes in democracy affect the political budget cycle?: Evidence for Mexico. Review of Development Economics 6: 204224.

[10] Lohmann, S. (1998a). Institutional checks and balances and the political control of the money supply. Oxford Economic Papers 30: 360-377.

[11] Lohmann, S. (1998b). Rationalizing the political business cycle: A workhorse model. Economics and Politics 10: 1-17. 
[12] Persson, T., Roland, G. and G. Tabellini. (1997). Separation of powers and political accountability. Quarterly Journal of Economics 112: 1163-1202.

[13] Persson, T. and G. Tabellini. (2000). Political Economics: Explaining Economic Policy. Cambridge, MA: MIT Press.

[14] Persson, T. and G. Tabellini. (2002). Do electoral cycles differ across political systems? Mimeo, IGIER, Bocconi University.

[15] Persson, T. and G. Tabellini. (2003). The Economic Effect of Constitutions: What Do the Data Say? Cambridge, MA: MIT Press (forthcoming).

[16] Romer, T. and H. Rosenthal. (1978). Political resource allocation, controlled agendas, and the status quo. Public Choice 33: 27-44.

[17] Romer, T. and H. Rosenthal. (1979). Bureaucrats vs. voters: On the political economy of resource allocation by direct democracy. Quarterly Journal of Economics 93: 563-588.

[18] Rosenthal, H. (1990). The setter model. In: Enelow, J. and M. Hinich (Eds.), Advances in the Spatial Theory of Voting. Cambridge: Cambridge University Press.

[19] Rogoff, K. and A. Sibert. (1988). Elections and macroeconomic policy cycles. Review of Economic Studies 55: 1-16.

[20] Rogoff, K. (1990). Equilibrium political budget cycles. American Economic Review 80: 21-36.

[21] Schuknecht, L. (1996). Political business cycles in developing countries. Kyklos 49, 155-70.

[22] Schuknecht, L. (1998). Fiscal policy cycles and public expenditure in developing countries. Working Paper ERAD-9806, Economic Research and Analysis Division, World Trade Organization.

[23] Shi, M. and J. Svensson. (2002a). Conditional political budget cycles. CEPR Discussion Paper 3352.

[24] Shi, M. and J. Svensson. (2002b). Political budget cycles in developed and developing countries. Mimeo, IIES, Stockholm University.

[25] Shi, M. and J. Svensson. (2003). Political budget cycles: A review of recent developments. Nordic Journal of Political Economy (forthcoming). 